\title{
Post-Modern Pavement: Theory, concept, performance and challenges
}

\author{
A. Jamshidi \& G. White \\ School of Science, Technology and Engineering, University of the Sunshine Coast, Queensland, Australia
}

\begin{abstract}
The Post-Modern Pavement (PMP) is a new concept in pavement design, construction, utility and recycling. It is conceptualised to address current and future challenges for various pavement types, such as asphalt, concrete and concrete block. The PMP is a novel method for categorising and evaluating pavements that serves as an interface between structural/environmental design, social requirements and human physiology in different service conditions. In this paper, the proposal of this category is premised upon a state-of-the-art study of pavement engineering history. The theories and concepts of PMP are presented, and the principles of PMP design and the challenges ahead are discussed. Results show that PMP is a multi-role pavement system that connects elements of transportation infrastructure assets into the ecosystem and public health.
\end{abstract}

Keywords: Structural performance, Sustainability, Multi-role infrastructure, Climate change, Urban design

\section{INTRODUCTION}

The evaluation of pavement performance is changing due to evolving demand of governments and the associated expectations of modern society. Pavements are no longer hard surfaces made of concrete and bituminous materials for transporting goods and passengers. As part of transportation infrastructure assets, pavements are the backbone of socioeconomic development. Hence, governments have invested huge capital in the construction, maintenance and rehabilitation of pavements. However, construction standards are being continuously upgraded to meet new requirements. For pavement engineers, the pavement system should adequately resist structural stress/strain induced by traffic loads and temperature gradients. Furthermore, pavements are inspected regularly to record structural and functional failures for planning maintenance and overhaul. In this regard, many laboratory tests, predictive models and field investigation protocols are carried out to analyse the bituminous/concrete mix in different transportation assets, including roads, ports and airports. Although the structural/functional performance of pavements is a key characteristic in such analyses, more variables should be considered due to the evolving attitudes in infrastructure development.

For many years, environmental engineers have criticised pavement engineers for paying insufficient attention to the ecosystem, thereby resulting in many natural disasters. As a result, eco-friendly materials and technologies have been developed to consider environmental concerns. New technologies and strict environmental regulations cannot fix all the consequences, but their development would be a great step taken towards sustainable practice in pavement design and construction. 
The development of pavement networks to support the rapid expansion of urban sprawl has resulted in a cost- and time-effective mode of transportation and, therefore, increased convenience and safety. In terms of social effects, feedback from pavement users plays a key role in the successful design and utility of pavements. Consequently, a new pavement categorisation method, termed the post-modern pavement (PMP) is proposed in this paper. The theories and concepts behind the PMP are also discussed briefly. The reason for introducing this category of pavement is explained via a review of pavement technology and science in different ages of urban design and human civilisation.

\section{HISTORY OF PAVEMENT}

\subsection{Birth and growth of pavement}

Binding materials such as bitumen and cement have been used since the dawn of civilisation. One of the first references to the use of bitumen was in Genesis 6:14, where the Lord told Noah, 'So make yourself an ark of cypress wood; make rooms inside it and coat it with pitch inside and out' (Roberts et al., 2002). Pitch is a sort of natural bitumen that floats to the surface of water bodies from fissures in the Earth's crust that leak crude oil. The crude oil exposed to sunlight loses its light oils and resins, resulting in a hard black or brown material by-product called bitumen. Bitumen was extensively used in Mesopotamia, Persia and Elam as mortar in the construction of buildings and coating roadways. It was likewise used to waterproof containers (baskets, earthenware jars, storage pits), wooden posts, flooring, reserves of lustral waters, bathrooms and palm roofs (Moorey, 1996). Mats, sarcophagi, coffins and jars used for funeral practices were often sealed using bituminous materials (Connan, 1999). In ancient Egypt, bituminous materials were used for mummification (Nissenbaum and Buckley, 2013, Clark et al., 2016). Therefore, people from the ancient age were already aware of the binding and sealing characteristics of bitumen as a construction and building material.

However, as bitumen was not an easily available material elsewhere, local materials such as cobblestone and brick were used as paving materials instead (ICPI, 2003). Relics of pavements can be found in the ancient cities of the Roman and Persian empires (Knapton, 1996; Hassani and Jamshidi, 2005; Zoccali et al., 2017). In this era, basic knowledge about natural raw materials for pavement construction was obtained from experience. The criteria for pavement design were based on the availability of materials and the application of roads. The main motivation for road construction was to develop safe and efficient routes for business, rapid and expedient communication across empirical territories and military movement. For example, the 2,669 km Royal Road was constructed to enable couriers to transmit administrative messages across the Persian Empire's territory in nine days (Axworthy, 2008). Labelling the Royal Road as the first highway in civilisation would not be an exaggeration. Another example is the Salt Road in the Roman Empire (Faktorovich, 2015). The road was constructed to transport salt, which was a strategic product because it was used as a food preservative to save people from famines.

The technology of pavement construction was mainly based on human power and animals, such as horses, mules and camels. There is no available detailed cost analysis of pavement construction from the dawn of civilisation to the 18th century. Note that the durability and structural resistance of pavement were the main criteria for pavement engineering.

\subsection{Enlightenment era of the pavement}

From the 18th to the 19th century, the empirical methods were developed that were based on the personal experiences gained by artists, architects, masons and craftsmen. In this timeframe, bigger carts rolled out, which required more durable road surfaces for efficient operation (Lilley, 1991).

The development of maritime transportation technology for military and civilian intercontinental transportation also necessitated the advancement of pavement technology. That 
is, the construction of ocean cruise ships was cutting-edge technology and played a key role in the exploitation and exploration of other continents (Uddin et al. 2013). To support the gigantic ships, new infrastructure assets were developed in the United Kingdom, Spain, Portugal, the Netherlands and France. One of the assets was the wharfs, which were often paved with wood and timber. Thus, the port pavement emerged to support evolving marine transportation.

At that time, paved roads were often made of cobblestone. Owing to the basic knowledge obtained and the initial understanding on the role of pavement as vital infrastructure to support different transportation modes, this age can be regarded as the enlightenment era of the pavement. Similar to the 18th century, the durability and structural resistance of pavement were the main concerns in pavement construction.

\subsection{Renaissance of pavement engineering}

In the 19th century, improvements in material technology accelerated the trend of pavement engineering. In addition, increased as a result of the rapid growth of manufacturing industries as a consequence of the Industrial Revolution. To prepare the roads for cars, more durable and resistant pavements were essential. Therefore, pavement engineers tried to identify the key design parameters and select the relevant design criteria.

The engineers likewise attempted to find the interrelations between design criteria and parameters through field and laboratory tests. In this regard, some initial laboratory tests were developed to simulate loads on the paving materials. Furthermore, the rapid development of railroad as another transportation mode helped in the development of testing facilities. For example, the Micro-Deval test (ASTM D6928) used to analyse the abrasion of ballast was primarily developed to analyse the abrasion characteristics of aggregate materials.

The theories developed by Winkler, Terzhagi, Westergard and Boussinesq had key roles in developing the initial analytical procedures for pavement design (Yoder and Witczack, 1975; Huang, 2005). It suggested that this age be referred to as the renaissance of pavement engineering because of the relatively rapid development of basic analytical knowledge on the characterisation of pavement materials and their engineering properties.

\subsection{Modern age of pavement engineering}

\subsubsection{Phase I (From 1900s to 1970s)}

The rapid development of oil fields in the United States and the Middle East resulted in the cost-effective production of petrol for vehicles. In the early 20 th century, the dominant transportation modes were railway and marine, both which were still powered by coal. The aviation industry was restricted to some commercial balloons and light aircraft developed by military sectors. After the second post-war period, demand for intercontinental air transportation increased.

Furthermore, the rate of car ownership skyrocketed in the United States and Europe in the 1950s (Croney \& Croney, 1991). As the axle weight of vehicles increased, it resulted in the higher stress/strain on pavement structures. Technological development achieved during the jet age also changed the gross weight of the main gear of aircraft and the wheel configuration. Owing to these changes, it was necessary to build more durable and stronger pavements for roads and airports. To tackle this problem, transportation agencies strove to develop guidelines for the structural design of pavements and the production of more durable materials. Polymer-modified binder, for example, was one of the products created to reduce distress on pavement surfaces. More detailed guidelines were developed to determine the thickness of various layers of bituminous and concrete pavements, eventually leading to the development of empirical-mechanistic design methods. In this regard, many administrative institutes and agencies were established in different countries to standardise materials and construction methods. 
Although material technology and structural design methods were improved, empirical methods, such as the California bearing ratio, continued to play a core role in engineering judgement. Given the variety of axle loads and types in vehicle and truck design, American Association of State Highway and Transportation Officials (AASHTO) undertook a longterm field test to estimate the damaging effects of various axles. The main objective of the test was to determine the relationship between the number of repetitions of a set of specific axle loads of various magnitudes and their arrangement. The output of the test was a set of proximity factors that convert all axle loads to a single-axle load of 8.20 tons (standard axle load). The factors were very useful for estimating the traffic load throughout the life span of a road pavement. The results of the AASHTO test serve as the backbone of pavement design in many countries.

Similarly, in airport pavements, the US Army Corps of Engineers (the Corps) conducted full-scale testing of trial aircraft pavements near Stockton, California. The result was an empirical pavement thickness design method to allow pavements to be developed to cater for the larger aircraft that were developed as a result of the WWII and the following Cold War period (White, 2017). This work later formed the basis of modern empirical-mechanistic design methods of aircraft pavements and full-scale testing continues under the direction of the Federal Aviation Administration (FAA) near Atlantic City, New Jersey, as aircraft continue to evolve.

In light of the breakthrough in computing method and data storage technology, some analytical methods and computer packages were developed to calculate the stress/strain and displacement of pavement layers. Therefore, pavement engineers were able to predict pavement response in terms of the stress/strain values and distribution patters. Additionally, the effect of axle type could be characterised through analysing the interaction between different wheels. ILLYSLAB, KENPAVE, BISAR and JSLAB are examples of the computer packages developed for pavement analysis.

In this age, new standards of testing materials were developed for selecting appropriate aggregate materials. Various tests were also used to characterise asphalt ageing, cement curing and rheology. Furthermore, performance-related tests were developed to characterise the structural response of asphalt and cement concrete mixtures. For example, new parameters such as resilient modulus and dynamic modulus were used to characterise the viscoelastic behaviour of asphalt mixture.

The development of mechanistic methods of analysis and design based on elastic theories and finite element resulted in more accurate numerical models to predict structural behaviour of pavements. In particular, structural design methodologies in Phase 1 became mature enough to address structural requirements under various utility conditions. Besides, practice standards and quality control protocols provided reliable outputs in the construction of flexible and rigid pavements.

\subsubsection{Phase II (From 1970s to 2020)}

The abundance of raw materials such as aggregates, along with the low price of crude oil, the main source of industrial fuel and bitumen resulted in the rapid development of transportation infrastructure assets. Although most concerns in the structural design and construction of pavements were addressed by the development of analytical approaches, a new challenge emerged in the 1970s. The oil shock that arose because of political challenges increased crude oil prices dramatically. Therefore, the initial activities to produce less energy- or materialintensive pavements began. For example, reclaimed asphalt pavement (RAP) technology was developed to produce cost-effective structural and surface layers. In other words, the development and implementation of RAP technology was largely a consequence of the energy crisis.

Environmental concerns were also raised in the public discourse because of global warming. To tackle the problem, stricter environmental regulations were prescribed to the construction industry by environmental policy makers and authorities. This means that structural design was no longer the single greatest challenge in pavement technology, being overtaken by global environmental concerns. The environmentalists encouraged pavement engineers and technologists to construct eco-friendly pavements that not only show high structural performance but 
also have lower environmental burdens in terms of greenhouse gas emission. To improve sustainability, a wide variety of industrial by-products and waste materials were used in pavement construction. For example, fly ash, blast furnace slag, cement kiln dust, demolished concrete and rubble were used in the concrete production.

Development of sustainable pavement technology accelerated during the first energy crisis in the 21st century. Unlike what happened in the 1970s, the second energy crisis was not caused by political challenges but by the lack of oil supply because the peak point of global oil production was expected to occur in the near future, or may have already occurred (Armstrong and Blundell, 2007). To address the energy crisis, warm mix asphalt (WMA) emerged as a sustainable asphalt technology that results in lower emissions and energy consumption. WMA production has increased because of promising results in the laboratory and the field. However, it should be noted that the trend of research and development on WMA depends significantly on the price of crude oil (Jamshidi and White, 2020).

There are various WMA additives and technology that reduce the mixing and compaction temperatures of asphalt through different mechanisms. For example, Sasobit ${ }^{\circledR}-W M A$ reduces total particulate emissions, $\mathrm{SO}_{2}, \mathrm{NOx}, \mathrm{CO}, \mathrm{CO}_{2}$, volatile organic compounds and benzene soluble matter levels by $74 \%, 83 \%, 21 \%, 63 \%, 42 \%, 51 \%$ and $80 \%$, respectively, in comparison with hot mix asphalt (Hurley et al., 2009). Moreover, the whole life emission of pavements, from the cradle to the grave, can be evaluated via rating systems such as life cycle analysis (LCA) and leadership in energy and environmental design (LEED). The results of LCA and LEED can be used to rank different pavement types and construction materials based on norms targeted by environmental and pavement agencies.

In Phase II of the modern age, a new category of pavement came on the stage that showed satisfying structural and functional performance as well as lower carbon footprint compared to traditional pavements. Therefore, the environmentally friendly pavement system emerged. This pavement category bridges the chasm between pavement and environment engineering. Environmental impact assessment became an inevitable part of paving projects worldwide, but it is impossible to embrace all environmental requirements. This consensus between pavement technology and the environment paves the way towards more sustainable practice.

In Phase II, the price of bitumen had again increased because oil refineries prefer to produce high value-added products over low-quality materials such as bitumen. Thus, the production of alternative binders is a practical strategy to reduce energy and raw material consumption in the pavement industry.

In the modern age, great improvements were achieved in the analysis of the engineering properties of paving materials. For example, Superpave and balanced mix design were developed to address new requirements of asphalt concrete based on field requirements. In this regard, new testing protocols and equipment were produced. For instance, Brookfield viscometer was produced to measure high-temperature properties of asphalt binders, while dynamic shear rheometer was designed on the premise of rheometers used in the plastic industry to evaluate binder properties from $0^{\circ} \mathrm{C}$ to $100^{\circ} \mathrm{C}$, where the binder displays viscoelastic behaviour.

Given that pavements are distressed over their life span, it is necessary to develop a pavement management system (PMS) for their maintenance and rehabilitation. PMS is a subsection of the asset management system, which is a useful support system for decision making by administrators, policy makers and engineers to consider the possible economic, social and environmental impacts of their investment decisions. Predictive models of distress were developed in the modern age to establish the optimum time frame of maintenance. Some computer packages were developed, such as the highway development and management model (HDM-4) and MicroPAVER. Note that PMSs and pertinent technologies vary in different countries because of administrative changes. For instance, monitoring airport construction has not been the responsibility of the Department of Housing and Construction in Australia since 1982 (White, 2016). Instead, the councils and the government of states are in charge of the operation, construction and design of airport pavements.

Pavements are impervious surfaces that decrease the permeability of catchments. Thus, the design of the drainage system in the vicinity of the pavement system is crucial. Construction 
of a permeable pavement is a practical measure integrating the pavement system and drainage. A permeable pavement system is a multi-role infrastructure asset that not only withstands the stress/strain induced by traffic loads but also drains the water that infiltrates. Therefore, it decreases the water head of the drainage system, which results in huge capital savings in urban development. The microbiological emission of runoff infiltrates through the permeable pavement can be decreased via specific geotextiles and fabrics (Imran et al. 2013; Scholz, 2013; Jiang et al. 2015). In other words, the pavement system can also act as hydraulic infrastructure for water treatment and storm water management.

However, permeable pavements have some drawbacks. For example, the porosity of the porous asphalt (PA) is relatively high, resulting in its lower structural capacity in comparison with the dense mix. Moreover, the binder creep phenomenon may lead to clogging (Hamzah et al., 2012). PA is usually used in parking lots and low traffic loads. Clogging is one of the factors that decrease the service life of permeable concrete and concrete block pavements. It depends on the hydrologic properties of catchment, hydraulic characteristics of aggregate materials, rainfall intensity, slope of the surface and amount of debris and organic waste materials on the pavement surface.

As a result, modern pavements are the interface between structural and environmental design (Figure 1). The weights of structural challenges and environmental concerns are almost identical. To think that current structural design and material characterisation methods do not need further updates and improvements is misleading and unrealistic. Pavement engineers and researchers still need to improve mechanistic methods and develop new materials with high structural consistency. More reliable predictive structural models of paving materials must be developed as well. For example, the Long-Term Pavement Performance (LTPP) programme can yield useful data for the evaluation of pavement performance.

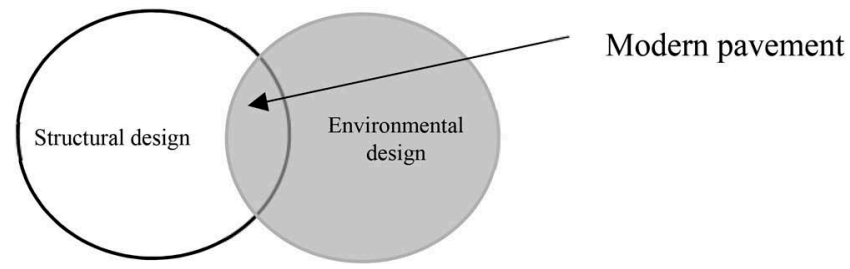

Figure 1. Definition of modern pavement as an interface between structural and environmental requirements.

\subsection{Post-modern pavement}

\subsubsection{Theory}

Although the structural performance of any pavement is a key factor in the life span of a pavement system, its functional performance, such as skid resistance, noise emission and evenness of the surface, is imperative for pavement users. Users do not care that pavement layers are determined through elastic or finite element approaches. Therefore, the concept of user-friendly pavements was developed. This kind of pavement describes a broad range of technologies, materials, monitoring system and construction methods that result in higherquality road surfaces.

To take the user-friendliness of pavements into account, in addition to the structural requirements and environmental necessities, the PMP was proposed. In other words, The PMP is a high strength and environmental-human friendly pavement.

\subsubsection{Concept}

Although there is some useful information on the utility condition of pavement surfaces, they are not able to characterise the effects of the environment on the users. Such characterisation 
is a new demand because urban sprawl has led to the urban heat island phenomenon, which results in higher human thermal load. Heat illness has been increasing in inner cities (Japan's Ministry of the Environment, 2017). To meet the demand, a new concept called humanfriendly pavement has been proposed. The human thermal load $\left(\mathrm{T}_{\mathrm{L}}\right)$ is characterised according to human physiological responses (Figure 2) and calculated through Equation (2).

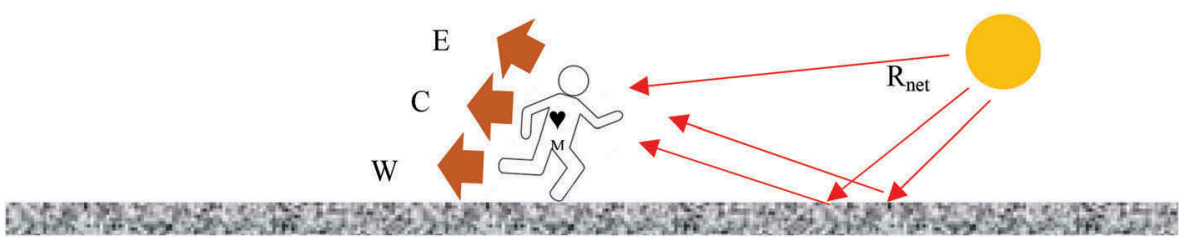

Figure 2. Schematic illustration of TL.

$$
\mathrm{T}_{\mathrm{L}}=\mathrm{M}-\mathrm{W}+\mathrm{R}_{\text {net }}-\mathrm{C}-\mathrm{E} \quad \text { Aoki et al.(2019) }
$$

$\mathrm{T}_{\mathrm{L}}$ : the human thermal load $\left(\mathrm{W} / \mathrm{m}^{2}\right)$

$\mathrm{M}$ : metabolic rate $\left(\mathrm{W} / \mathrm{m}^{2}\right)$ which is calculated from body surface area, oxygen intake and carbon dioxide production

$\mathrm{W}$ : work load $\left(\mathrm{W} / \mathrm{m}^{2}\right)$ which is the amount external work the human body carries out

$\mathrm{R}_{\text {net }}$ : net radiation $\left(\mathrm{W} / \mathrm{m}^{2}\right)$ which is amount of solar and infrared radiation absorbed and gives by human body

C: sensible thermal loss $\left(\mathrm{W} / \mathrm{m}^{2}\right)$ which is due to difference between skin and ambient temperature as well as thermal exchange via respiration;

E: latent heat loss $\left(\mathrm{W} / \mathrm{m}^{2}\right)$ which is due to sweating, expiration and insensible perspiration

The user-friendly pavement is not a new concept, originally dating back to the AASHTO tests in the late 1950s. In addition, Carey and Irick (1960) conceived the pavement serviceability rating (PSR) as a key criterion of pavement to serve pavement users. Later, PSR was replaced with the pavement serviceability index (PSI), which ranges from 0 to 5 . The highest score denotes a new constructed pavement, which decreases over time, while the lowest score denotes a fully distressed surface. PSI and international roughness index (IRI) are two quality indicators of the pavement surface. The main objective of user- or human-friendly pavements is to make a comfortable and safe environment for pavement users (Figure 3). This comfort can be in terms of a healthy and safe environment for pavement users. Another example is age-friendly pavement, which was proposed by the World Health Organization (WHO, 2007) to prepare cities for global population ageing.

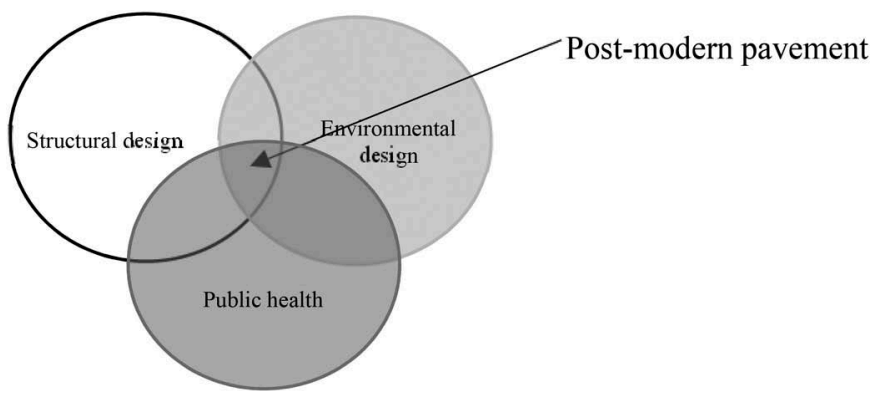

Figure 3. Definition of PMP as an interface between structural, environmental and social requirements. 


\subsubsection{Performance and challenges}

To improve the utility condition of users, different technologies and materials have been developed for asphalt, concrete and concrete block pavement systems. For example, a waterretaining block pavement surface was proposed to decrease $T_{L}$. Figure 4 shows that the $T_{L}$ of water-retaining blocks was lower than that of asphalt. Therefore, concrete block pavement is human-friendly pavement. In contrast, the construction of concrete block pavement is costly, and the level of noise emission of such pavement is higher than those of asphalt and concrete pavements (Karasawa et al., 2000; Ishai, 2003). The PMP concept allows these advantages and disadvantages to the objectively compared to those associated with other pavement or surface types.

To increase the reflection of the pavement surface, different types of high reflectance coating are used. The reflection of the coating results in less thermal energy being absorbed by the pavement surface. An estimated $50-60 \%$ of roofs and pavements in urbanised areas can be treated using coating ( $\mathrm{Li}$ and $\mathrm{Xie}, 2020$ ). In an experimental study, fluorinated acrylate coating increased the albedo of samples by $79 \%$, and the sample temperature was reduced by $13^{\circ} \mathrm{C}$ when the normal asphalt mixture approached $60^{\circ} \mathrm{C}$ (Cao et al., 2017). Although coating is a cost-effective technology that can be adopted for various alternative pavements, its durability is a matter of concern. In addition, some coating materials decrease surface friction, which affects the level of safety. Lower friction would be underscored when the surface of the coated pavement becomes wet.

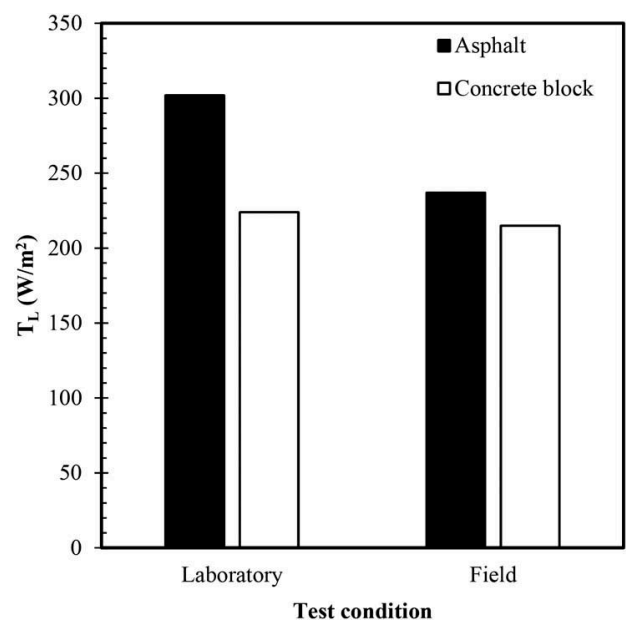

Figure 4. $\mathrm{T}_{\mathrm{L}}$ of different alternative pavements, plotted based on the data reported by Aoki et al. (2019).

\section{CONCLUSION}

The structural performance of pavements was a serious engineering issue for many years. The experiences and technical knowledge gained during the renaissance, enlightenment and modern ages of pavement history resulted in breakthroughs in the material characterisation and structural design of different alternative pavements. However, environmental disasters and energy challenges opened a new frontline. In the modern age, pavement engineers must consider both structural and environmental requirements. In the future, the user-friendliness of pavement must also be considered and the PMP has been conceptualised to enable this. The PMP recognises pavements as a multi-role infrastructure or an integrated system that not only has high structural capacity against traffic loads but also has high sustainability due to 
its use of recycled and porous materials for water drainage and treatment. In addition, the PMP can improve public health via the enhancement of surface reflectivity and the like. Therefore, it is necessary to design a PMP based on the new concept called human-infrastructure interface, which is similar to the concept of human-machine interface based on ergonomic principles. The PMP is a new terminology in pavement history that opens new horizons in research and engineering. As a result, it is necessary to propose standards and practice codes to consider structural, environmental and social requirements for PMP, using LCA and LEED concepts calibrated against LTPP models.

\section{REFERENCES}

American Society for Testing and Materials (ASTM) D6928, 2014., Standard test method for resistance of coarse aggregate to degradation by abrasion in the Micro-Deval apparatus, Conshohocken, Pennsylvania, USA, 2014

Aoki, M., Nakamura, T., \& Shimazaki, Y., 2019. Experimentally investigation of the effect water retentive sidewalks block pavement on improving thermal environment, the 12th International Conference on Concrete Block Paving, Seoul, South Korea,150-160.

Armstrong, F.A., and Blundell, K.M., 2007. Energy... Beyond Oil. Oxford University Press, UK.

Axworthy, M., 2008. Iran: Empire of the mind: A history from Zoroaster to the present day, Penguin UK.

Cao, X., Tang, B., Luo, T., \& Guo, P., 2017. Preparation of fluorinated acrylate coating with high albedo and its cooling effect on asphalt mixture, Road Materials and Pavement Design, 18(2), 464-476.

Carey, W.N., \& and Irick. P.E., 1960. The pavement serviceability performance concept, Highway Research Board. Record 250, Washington, USA.

Clark, K. A., Ikram, S., \& Evershed, R. P., 2016. The significance of petroleum bitumen in ancient Egyptian mummies, Philosophical Transactions of the Royal Society A: Mathematical, Physical and Engineering Sciences, 374(2079), 20160229.

Connan, J., 1999. Use and trade of bitumen in antiquity and prehistory: molecular archaeology reveals secrets of past civilizations, Philosophical Transactions of the Royal Society of London. Series B: Biological Sciences, 354(1379), 33-50.

Croney, D., \& Croney, P., 1991. The design and performance of road pavements, McGrow Hill, New York, USA.

Faktorovich, A., 2015. SPQR: A History of Ancient Rome, Pennsylvania Literary Journal, 7(3), 61.

Hamzah, M. O., Hasan, M. R. M., \& van de Ven, M. 2012., Permeability loss in porous asphalt due to binder creep, Construction and Building Materials, 30, 10-15.

Horvli, I. and Garba, R. 2002., Permanent deformation properties of asphalt concrete mixture, Proceedings of the Sixth International Conference on the Bearing Capacity of Roads, Railways, and Airfields, Lisbon, Portugal.

Huang, Y.H., 2004. Pavement Analysis and Design, Pearson, New York, USA.

Hurley, GC., Prowell, BD., Kvasnak, AN., 2009. Michigan field trial of warm mix asphalt technologies: construction summary, National Center for Asphalt Technology, Auburn, AL, USA.

ICPI., 2003. Structural design of interlocking concrete pavements for roads and parking lots, Tech.Spec. 4, Interlocking Concrete Pavement Institute, Washington, DC, U.S.A.

Imran, H. M., Akib, S., \& Karim, M. R., 2013. Permeable pavement and stormwater management systems: a review. Environmental technology, 34(18), 2649-2656.

Ishai, I. (2003. Comparative economic-engineering evaluation of concrete block pavements, Road Materials and Pavement Design. 4 (3), 251-268.

Jamshidi, A., \& White, G., 2020. The Challenges of warm mix asphalt as a mature technology. In Proceedings of the 9th International Conference on Maintenance and Rehabilitation of Pavements-Mairepav9. Springer, Cham.

Jamshidi, A., and Hassani, A., 2006. The principles of performance, design and construction of concrete block pavements, Aradmehr Publication, Tehran, Iran.

JIEPA.,2017. Japan interlocking block pavement design and construction manual, 2017. Japan Interlocking Pavement Engineering Association, Tokyo, Japan, (In Japanese).

Jiang, W., Sha, A., Xiao, J., Li, Y., \& Huang, Y. 2015. Experimental study on filtration effect and mechanism of pavement runoff in permeable asphalt pavement, Construction and building materials, 100, $102-110$. 
Karasawa, A., Kagata, M., \& Ezumi, N., 2000. Performance evaluation of the low noise drainage interlocking block pavement system applied to the driveway, the 6th International Conference on Concrete Block Paving, Tokyo, Japan, pp. 552-561.

Knapton, J., 1996. The Romans and their roads-The original small element pavement technologists, in: 4th International Conference on Concrete Block Paving, Delft, Netherland, pp. 17-52.

Li, H., \& Xie, N., 2020. Reflective coatings for high albedo pavement, In Eco-Efficient Pavement Construction Materials. Woodhead Publishing, New York, USA.

Lilley, A. A., 1991. A handbook of segmental paving, E \& FN Spon. London, UK.

Ministry of the Environment of Japan. 2017. Heat illness prevention information site, Health manual on heat illness environment, http.wbgt.env.go.jp/heatstroke_manual.php.

Moorey, R., 1994. Ancient Mesopotamian materials and industries, Oxford: Clarendon Press.

Nissenbaum, A., \& Buckley, S. 2013. Dead sea asphalt in ancient Egyptian mummies-why? Archaeometry, 55(3), 563-568.

Roberts, F. L., Mohammad, L. N., and Wang, L. B., 2002. History of hot mix asphalt mixture design in the United States, Journal of Materials in Civil Engineering, 14(4), 279-293.

Scholz, M. 2013. Water quality improvement performance of geotextiles within permeable pavement systems: A critical review, Water, 5(2), 462-479.

Uddin, W., Hudson, W. R., \& Haas, R. C., 2013. Public infrastructure asset management, McGraw Hill Professional, New York, USA.

White, G., 2017. Airfield pavement essentials. Australian Airport Association, Airport practice note, Canberra, Australia, 1-96. PDF file. September 18, 2020: http://airports.asn.au/wp-content/uploads/2018/ 04/Airport-Practice-Note-12_05_lowres.pdf

White, G., 2016. Challenges for Australian flexible airport pavements, Aust. Geomech, 51(3), 39-46.

World Health Organization., 2007. Global age-friendly cities: A guide, World Health Organization. Geneva, Switzerland.

Yoder, E.J. and Witczak., M.W., 1975. Principles of Pavement Design, John Wiley \& Sons, New York, USA.

Zoccali, P., Loprencipe, G., \& Galoni, A., 2017. Sampietrini stone pavements: distress analysis using pavement condition index method, Applied Sciences, 7(7), 669. 